\title{
Effect of Pressure and Heat Treatments on the Compressive Strength of Reactive Powder Concrete
}

\author{
Masdar Helmi ${ }^{1, *}$, Matthew R Hall ${ }^{2,3}$, and Sean P Rigby ${ }^{4}$ \\ ${ }^{1}$ Department of Civil Engineering, Faculty of Engineering, University of Lampung, Jalan S. Brojonegoro No. 1 Bandar \\ Lampung, Indonesia 35145 \\ ${ }^{2}$ GeoEnergy Research Centre, Faculty of Engineering, University of Nottingham, University Park, Nottingham NG7 2RD, UK \\ ${ }^{3}$ British Geological Survey, Environmental Science Centre, Keyworth, Nottingham NG12 5GG, UK \\ ${ }^{4}$ Division of Manufacturing and Process Technologies, Faculty of Engineering, University of Nottingham, University Park, \\ Nottingham NG7 2RD, UK
}

\begin{abstract}
This paper presents the corresponding compressive strength of RPC with variable pressure combined with heating rate, heating duration, and starting time of heating. The treatments applied were $8 \mathrm{MPa}$ static pressure on fresh RPC prims and heat curing at $240{ }^{\circ} \mathrm{C}$ in an oven. The compressive strength test was conducted at 7-d and 28-d. The images of RPC morphology were captured on the surface of a fractured specimen using Scanning Electron Microscopy in Secondary Electron detector mode to describe pore filing mechanism after treatments. The results show that a heating rate at 50 ${ }^{\circ} \mathrm{C} / \mathrm{hr}$ resulted in the highest compressive strength about $40 \%$ more than those at 10 or $100{ }^{\circ} \mathrm{C} / \mathrm{hr}$. A heating duration of 48 hours led to the maximum compressive strength. Heat curing applied 2 days after casting resulted in the maximum compressive. Heat curing had a signicant effect on the compresssive strength due to the acceleration of both reactions (hydration and pozzolanic) and the degree of transformation from tobermorite to xonotlite. It is concluded that the optimum condition of treatments is both pressure and heat curing at 2-day after casting with a rate of $50{ }^{\circ} \mathrm{C} / \mathrm{hr}$ for 48 hours.
\end{abstract}

\section{Introduction}

Reactive powder concrete (RPC), categorized as a type of ultra-high performance concrete (UHPC) due to having compressive strength $>140 \mathrm{MPa}$, has a different composition to ordinary concrete. RPC has no coarse aggregate and contains a higher proportion of fine particles $(<600 \mu \mathrm{m})$ comprising silica fume, quartz sand and other admixtures. RPC can be developed by controlling three main variables: composition, pressure during setting period, and post-set heat curing [1].

Firstly, composition can be improved through a microstructural engineering approach by using fine aggregate only (no coarse aggregate), reducing waterbinder ratio, lowering the $\mathrm{CaO}-\mathrm{SiO}_{2}$ ratio through the introducing of silica-rich pozzolona [2,3] and adding fibre reinforcement to increase ductility [4]. Secondly, pressure applied during the setting period also influences the strength of concrete. Pressure induces three main effects: reducing the entrapped air, removing the excess water, and eliminating the porosity caused by chemical shrinkage [1]. Meanwhile, heat curing induces the acceleration of the pozzolanic reaction between amorphous silica and calcium hydroxide as well as the silicate and aluminate hydration reaction, and also the modification of hydrate microstructure $[5,6]$.

An RPC mixture typically contains a high amount of cement at a dosage of $800-1000 \mathrm{~kg} / \mathrm{m}^{3}$. The use of cement in a high amount impacts on the heat of hydration and leads to potential risks associated with shrinkage and creep-induced strain problems, and also the production cost. To solve the cost problems, Yazici et al., [7] conducted research on the composition of RPC mixtures to find the optimal amount of finer materials from industrial waste (SF, PFA, and GGBS) as cement replacement. They suggested that RPC comprising $35 \mathrm{wt} \% \mathrm{SF}$ and up to $40 \%$ GGBS (as cement replacement) could result in a compressive strength of more than 200 MPa. However, the presence of mineral admixtures can slow down the hydration reaction, lower the heat of hydration, and decrease shrinkage. This is often a difficult problem to overcome in mixtures with high cement content and low water/cement ratios [8].

Most scholars have argued that the strength of RPC is mainly developed by the pozzolanic reaction and hydrate transformation after heat curing. Heat curing, which is one of the most important treatments in RPC, can be applied by various methods. Yazici et al [7] applied heat curing on RPC prism specimens (after demoulding) in an autoclave at $2.0 \mathrm{MPa}$ and $210^{\circ} \mathrm{C}$. These conditions were achieved within a $2.5 \mathrm{~h}$ heating period, and the heat curing was then applied for 8 hours. Cwirzen [6] used a method of steam curing $\left(95 \% \mathrm{RH}, 90{ }^{\circ} \mathrm{C}\right)$ to optimise the conditions for heat curing by varying two factors: the starting time of heating after demoulding, and the duration of heating. Heat curing was applied to the RPC cube specimens with durations of 24,48 and 168 hours, and starting times at 1,2 , and 4 days after casting the samples.

* Corresponding author: masdar.helmi@eng.unila.ac.id 
He suggests that the optimal conditions of heating can be reached after 2 days of casting with a total duration of 48 hours producing the highest degree of hydration. Another heat curing method was applied by Sadrekarimi [9] and Tam et al. [10] in drying oven equipment with different rates and maximum temperatures. Sadrekarimi [9] placed samples in the oven with a constant heat rate of $10^{\circ} \mathrm{C} / \mathrm{hr}$ until it reached a temperature of $240{ }^{\circ} \mathrm{C}$. Tam et al. [10] set first a drying oven at $100^{\circ} \mathrm{C}$ then placed samples into the oven with a temperature rate of $50{ }^{\circ} \mathrm{C} / \mathrm{hr}$ until it reached $250{ }^{\circ} \mathrm{C}$. It should be noted that the duration and heating rate are important factors in heat curing since they affect the crystallisation of hydrates, pozzolanic reaction, microstructure development and associated bulk mechanical properties [11].

Heat curing treatment, which is generally applied after final set of cement at a temperature between $90{ }^{\circ} \mathrm{C}$ and $250{ }^{\circ} \mathrm{C}$, contributes to both the progression of cement hydration and the acceleration of the pozzolanic reaction between silica fume (amorphous) and quartz flour (crystalline) $[12,5,6,11]$. Heat curing also modifies the micro structure of hydrates by changing the $\mathrm{C}-\mathrm{S}-\mathrm{H}$ chain length from trimer to pentamer [6]. When the temperature of curing increases to more than $200{ }^{\circ} \mathrm{C}$, this condition leads to the transformation of crystalline hydrates and dehydration of the hardened paste. The transformation hydrate will be formed spontaneously when water extracted from hydrates is trapped in the centre of samples during transient heating [12] becoming tobermorite at a temperature of $150{ }^{\circ} \mathrm{C}$ and xonotlite at temperatures of both 200 and $250^{\circ} \mathrm{C}$ [11].

It is clearly understood that the treatments of pressure and heat curing affect the strength of RPC which depend on three factors; the method of application, the temperature and duration of treatments [13]. Cwirzen [6] and Tam \& Tam [11] have studied the effect of treatments on RPC containing high cement content with those variables. They used the composition of RPC with high cement content and not yet in low cement content due to using industrial waste as cement replacement. Therefore it is necessary to evaluate the optimisation of treatments on RPC mixtures.

\section{Experimental method}

\subsection{Materials}

The main binder was CEM1 52.5 cement (Rugby, Cemex UK), in accordance with BS EN 197-1:2011. The silica fume was used along with microsilica grade 940-D (Elkem, Switzerland) and Ground Granulated Blastfurnace Slag (GGBS) (Hanson, UK) was used as a partial cement replacement. Quartz sand (David Ball Ltd. UK) was used where, $G=2.65$ and water absorption $=1.5$ $\%$, with gradation conforming to BS 1881-131. This study used three grades of sand: A $(2.36 \mathrm{~mm}-1.18 \mathrm{~mm}), \mathrm{C}$ $(0.60 \mathrm{~mm}-0.30 \mathrm{~mm})$ and $\mathrm{E}(0.15 \mathrm{~mm}-0.09 \mathrm{~mm})$. These grades were mixed in a ratio of $2 \mathrm{~A}: 1 \mathrm{C}: 1 \mathrm{E}$ (by mass) to produce a suitable particle size distribution as suggested by Yazici et al. [7].

\subsection{Sample fabrication}

The composition used industrial waste due to the fact that this technique can reduce the use of cement by up to 40 $\%$, while giving compressive strength of more than 200 $\mathrm{MPa}$ [7]. A trial mix was done in order to get enough workability of fresh RPC mixture. Table 1 presents the result of the final composition.

The mixing of RPC containing very fine materials and low water-cement ratio is different from a conventional concrete mixing process. The process of mixing in this study was adopted from [8]. Initially, dry materials, including binder and quartz sand, were put in a stainless mixer bowl, mixed at a speed of $\sim 120 \mathrm{rpm}$ for 2 minutes and then followed by mixing with a speed of up to $\sim 450$ rpm for another 2 minutes. The half volume of water and SP premixed were then added and mixed for about 5 minutes until the mixture had a consistent appearance. After the mixture became consistent, it was cast into oiled steel moulding which contained three prisms with dimension of $40 \times 40 \times 160 \mathrm{~mm}$.

Table 1. Composition of RPC per cubic meter

\begin{tabular}{|c|c|c|c|c|c|c|c|}
\hline \multirow{2}{*}{$\begin{array}{c}\text { PC } \\
(\mathrm{kg})\end{array}$} & \multirow{2}{*}{$\begin{array}{c}\text { SF } \\
(\mathrm{kg})\end{array}$} & \multirow{2}{*}{$\begin{array}{c}\text { GGBS } \\
(\mathrm{kg})\end{array}$} & \multicolumn{3}{|c|}{ Quartz $(\mathrm{kg})$} & \multirow{2}{*}{$\begin{array}{c}\text { Water } \\
(\mathrm{kg})\end{array}$} & $\begin{array}{c}\text { SP } \\
(\text { litre })\end{array}$ \\
\hline 498 & 208 & 332 & 488 & 244 & 244 & 200 & 55 \\
\hline
\end{tabular}

\subsection{Sample treatments}

\subsubsection{Pressure treatment}

Pressure treatment was used to compact RPC samples in the setting period. Static pressure was applied on the top of fresh mixtures using a compressive machine for about 5 hours after casting. The load was increased and controlled by a computer at a rate $1 \mathrm{kN} / \mathrm{s}$ to reach at 150 $\mathrm{kN}$, which resulted in a stress of $8 \mathrm{MPa}$ for each sample. The compressive machine was held in this load position for about 2 minutes in order to tighten four corner bolts in the moulding. Using this method will allow the load to continue pressing the samples during the setting period [13]. Releasing the pressure and demoulding the samples was done after 48 hours of casting in order to let the mixture harden properly and not stick to the moulding [10]. Figure 1 presents the illustration of the mould and the samples.

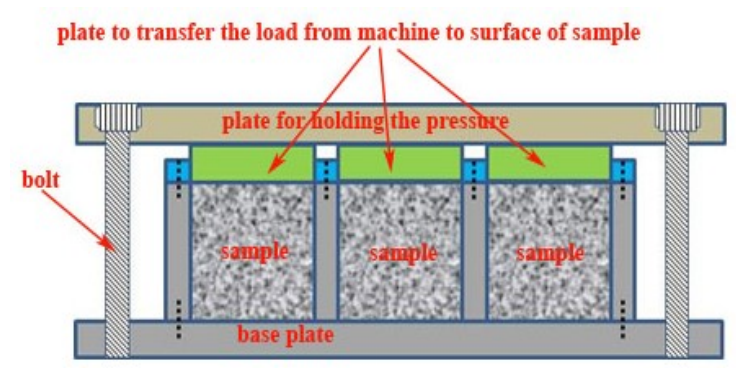

Fig. 1. Cross section of mould with pressure. 


\subsection{Heat curing treatment}

Heating the sample in the setting period is a unique treatment for RPC, which is different from treatments in common concrete [13]. The heat curing process in this study uses a drying oven similar to an experiment by [10]. The samples are put on a rack and preheated at $40{ }^{\circ} \mathrm{C}$ for 2 hours, and then increased to $240{ }^{\circ} \mathrm{C}$. The rate, durations, and starting time of heating were used as variables in the preliminary study to get the optimum condition which were indicated by compressive strength. There were three different levels in every set; rates were 10, 50, and 100 ${ }^{\circ} \mathrm{C} /$ hour; durations were 12,24 , and 48 hours; and starting times were 1, 2, and 3 days. After heat curing finished, the temperatures of the oven was decreased at $2{ }^{\circ} \mathrm{C} / \mathrm{min}$ rate to $40{ }^{\circ} \mathrm{C}$, then samples were cooled at room temperature. The samples were then submerged in water at a temperature of $10{ }^{\circ} \mathrm{C}$ until the day of testing, either $7-\mathrm{d}$ or 28-d.

\subsection{Method of testing}

\subsubsection{Compressive strength}

The compressive strength test was conducted at 7-d or 28$\mathrm{d}$ using one part of the two broken pieces of prism conforming to BS EN 196-1:2011. The contact pressed area of the sample was $40 \times 40 \mathrm{~mm}$ and the height was 40 $\mathrm{mm}$. The samples were tested at 7-d and 28-d under compressive machine with a maximum capacity of 500 $\mathrm{KN}$ and load rate of $2400 \mathrm{~N} / \mathrm{s}$. This test results in the maximum load, which was then used to calculate compressive strength by dividing it by the surface of the contact area. The average of compressive strength is taken from three samples.

\subsubsection{Paste morphology}

Samples for SEM tests were made from fractured bulk specimens of RPC cubes. Three representative subsamples were mounted fracture face down and cold mounted under vacuum in 2-part epoxy resin. Mounted samples were ground using $\mathrm{SiC}$ paper $(400,600,800$ and 1200 grit) on $20 \mathrm{~cm}$ diameter wheels at a rotational speed of $250 \mathrm{rpm}$, followed by polishing using $6 \mu \mathrm{m}$ then $1 \mu \mathrm{m}$ diamond pastes. Polished samples were washed using acetone and dried under a hot air blower, followed by sputter coating with $\sim 15 \mathrm{~nm}$ thick carbon using an Edwards 306 vacuum Coater, as shown in Figure 2.

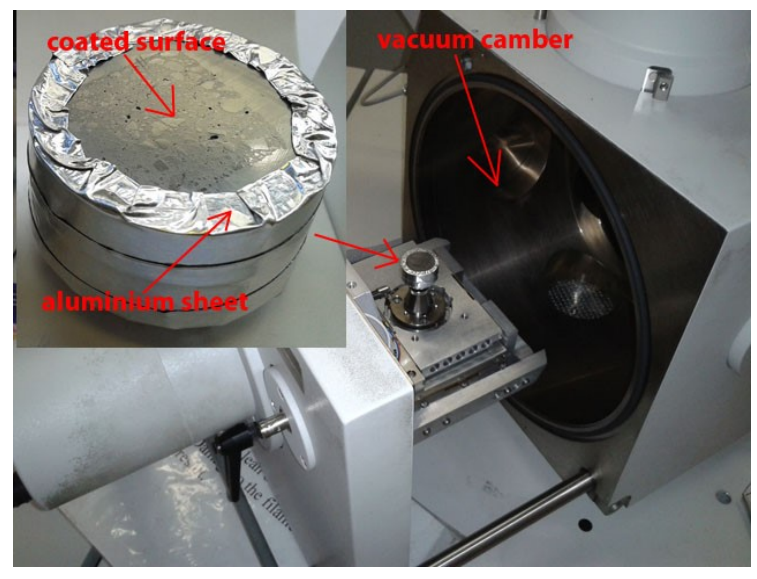

Fig. 2. Placing the mounted and coated sample in vacuum camber.

\section{Result and Discussion}

\subsection{Compressive strength due to heating rate}

The heating rate has a correlation with the speed of evaporation, this in turn influences the extent of air voids and hydration reaction in the concrete (Sadrekarimi, 2004). A low heating rate may decrease the dehydration rate by allowing sufficient time for thermal diffusion to occur, which influences the final compressive strength of the concrete. Therefore three different rates, namely 10 , 50 and $100{ }^{\circ} \mathrm{C} / \mathrm{hr}$ were evaluated in this study. Samples were tested in compression at 7-d and 28-d using two parts of a broken prism. The result is shown in Figure 3.

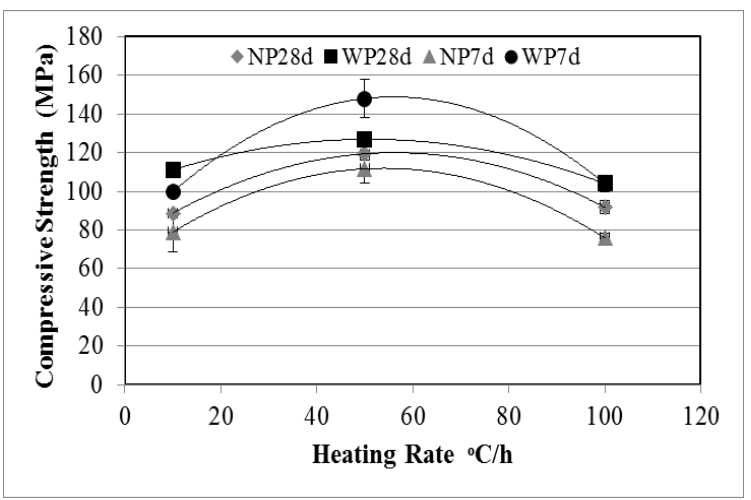

Fig. 3. Compressive strength-heating rate curves for a heating duration of 48 hours after 2 days of casting.

The compressive strength, at 7-d and a heating rate of 10 ${ }^{\circ} \mathrm{C} / \mathrm{hr}$, is $79 \mathrm{MPa}$ for a non-pressured (NP) sample and 100 $\mathrm{MPa}$ with pressure (WP) [14]. This is stronger than the qualification of high strength concrete performance (HSCP) according to Neville [15]. At 28-d, the compressive strength continuously increases up to 89 $\mathrm{MPa}$ for NP and $111 \mathrm{MPa}$ for WP. When the heating rate is increased to $50{ }^{\circ} \mathrm{C} / \mathrm{hr}$, the compressive strength at $7-\mathrm{d}$ 
increases by $41 \%$ (NP) and by $48 \%$ (WP) compared to the numbers achieved for the $10{ }^{\circ} \mathrm{C} / \mathrm{hr}$ samples.

At 28-d, however, compressive strength remains relatively stable for NP and drops about $14 \%$ for WP compared to the same samples is at 7-d. It is supposed that the hydration and pozzolanic reactions have been accelerated with the application of heat but that micro cracks are also produced. Increasing the heat application level to $100{ }^{\circ} \mathrm{C} / \mathrm{hr}$ has less effect on compressive strength compared to using $10{ }^{\circ} \mathrm{C} / \mathrm{hr}$. Compressive strength changes at this heat rate, either at 7-d or 28-d for both NP and WP, are within the calculated range of error for the measured results and can be ignored.

The lack of change in compressive strength with high temperature could mean that the high rate heating induces immediate evaporation of water from the C-S-H gel and causes a rapid increase in the pressure of pores which in turn increases the tensile stress in the cement paste. If this tensile stress is higher than the tensile capacity of RPC at 2-d (the point at which pressure is applied) microcracks are induced around the pores. Microcracks, which have been formed during the setting period due to natural shrinkage and grain movement after pressure application, could increase in number and width after heat curing. Consequently, the reason for achieving lower compressive strength in samples with heating rates of 10 and $100{ }^{\circ} \mathrm{C} / \mathrm{hr}$ could be less effective hydration and pozzolanic reactions and the development of microcracks respectively [1].

\subsection{Compressive strength due to heating duration}

For this experiment, samples were heated to a maximum temperature of $240{ }^{\circ} \mathrm{C}$ with a ramp rate of $50{ }^{\circ} \mathrm{C} / \mathrm{hr}$ in a drying oven. The maximum temperature was applied for durations of 12, 24 and $48 \mathrm{~h}$. The measured compressive strengths in the samples at 7-d and 28-d are presented in Figure 4.

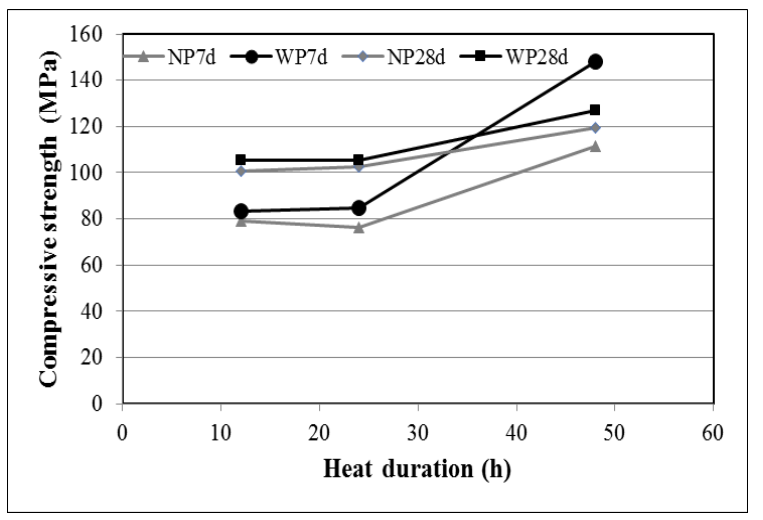

Fig. 4. Compressive strength-heating duration curves for a heat rate of $50{ }^{\circ} \mathrm{C} / \mathrm{hr}$ after 2 days of casting.

As can be seen in Figure 4, the curve shows that there is no optimum compressive strength from the three variations of heat duration tested. However, the compressive strength tends to increase with an increase of duration for all samples. At 7-d, the compressive strength increases progressively and not linearly with heating duration. It is found that the compressive strength of samples with heating duration of 12,24 and $48 \mathrm{~h}$ are 79.02, 76.34, 111.60 MPa for NP and 83.20, 84.62, 147.94 MPa for WP, respectively. The difference is less significant at $12 \mathrm{~h}$ compared to $24 \mathrm{~h}$ and becomes very significant to $48 \mathrm{~h}$ as there is increase of around $45 \%$ (NP) and $75 \%$ (WP). For the 28 day samples the trend is more gradual with the difference in compressive strength of both types of sample at around $20 \%$.

This result shows that the duration of heating is an important factor which affects the compressive strength of RPC and the properties of the microstructure [6]. The effect shows correlation with the acceleration of the rate of cement hydration and pozzolanic reactions for both silica fume and quartz sand. In addition, the duration of heat condition results in an increase in the strength of the $\mathrm{RPC}$ due to the amount of C-S-H produced and the change in crystal formation from tobermorite to xonotlite [11].

\subsection{Compressive strength due to heating start time}

For this experiment, three samples were heated under identical temperature conditions of $240{ }^{\circ} \mathrm{C}$ at a ramp rate of $50{ }^{\circ} \mathrm{C} / \mathrm{hr}$ in a drying oven. The time of sample placement in the oven after casting was varied between samples with delays of 1,2, and 3 days. The comparison of compressive strengths for the three different delay times at 7-d and 28-d is presented in Figure 5.

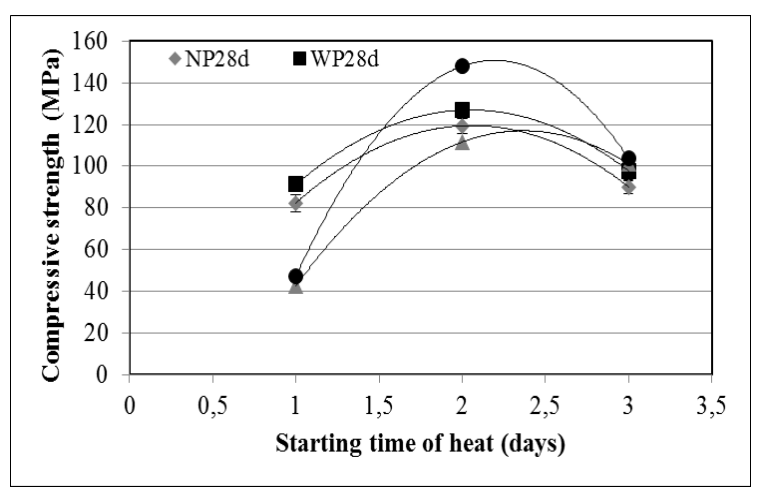

Fig. 5. Compressive strength-heated starting time curve for heating rate of $50{ }^{\circ} \mathrm{C} / \mathrm{hr}$ and duration of $48 \mathrm{~h}$.

Figure 5 shows that the optimum compressive strength is found when the heat condition is applied after a delay of 2 days from casting, both at 7-d and 28-d, for both NP and WP samples. Although the rate of strength development in concrete under normal curing conditions is influenced by the rate of hydration after one or two days [14], it will still increase gradually with time [16]. The results from applying heat curing in RPC samples at 3 days show disagreement with this theory, with a contradictory result of a $45 \%$ reduction in compressive strength compared to the one with applied heat curing after 2 days. In any condition, the compressive strength of WP samples was always higher than NP samples for all conditions because 
pressure condition changes the physical microstructure of the mixture before final setting was achieved by a densification mechanism [1].

The reason for optimum compressive strength being achieved by heating at 2 days may be explained by hydration theory [16]. On the first day of hardening, tobermorite $[\mathrm{C}-\mathrm{S}-\mathrm{H}]$ gel was formed in much higher quantities than ettringite and portlandite $\left[\mathrm{Ca}(\mathrm{OH})_{2}\right]$ and starts to form $\mathrm{C}_{4} \mathrm{AF}$ hydrate. During the second day, the volume of hydrated phases increased and the volume of ettringite decreased as it converted to monosulphate, and on the third day the density of hydrate phases began to increase significantly. Moreover the majority of ettringite converted to monosulphate prior to the onset of the hydrate phase densification at 2 days. Given that the above was a valid description. This suggests that the highest compressive strength, while heat curing was applied at 2 days, could be due to acceleration of hydrate phase densification whilst the risk of microcracks initiation/ enlargement resulting from thermal expansion of partially-hardened hydrate phases was avoided.

\subsection{Morphology of cement paste}

It is well known that pressure setting applied to fresh RPC mixtures can increase their density due to the reduction of entrapped air pores, both in terms of diameter and number, and the associated removal of free water content. On the other hand, the use of high cement content and low water-cement ratio results in a mixture of anhydrous and hydrated material. In addition, applying high temperature curing affects not only the prevention of the hydration process of cement grains but also induces microcracks in the hardened paste due to evaporation and the transformation of CSH gel [10].

\subsubsection{Entrapped air pores}

In general RPC has a denser matrix phase and is more homogeneous than normal concrete. However it still contains entrapped air pores with a wide range of diameters between 10 and $300 \mu \mathrm{m}$, which are formed by using high amounts of superplasticizer in the RPC mixture [8]. Entrapped air pores are generally spherical and much larger than any other type of pore.

In SEM images of cementitious materials, several kinds (and length scales) of pores can be observed as shown in Figure 6 - 9. Polished cross-section RPC specimens were prepared and imaged, and analysed using the secondary electron (SE) detector at $10 \mathrm{~mm}$ working distance.

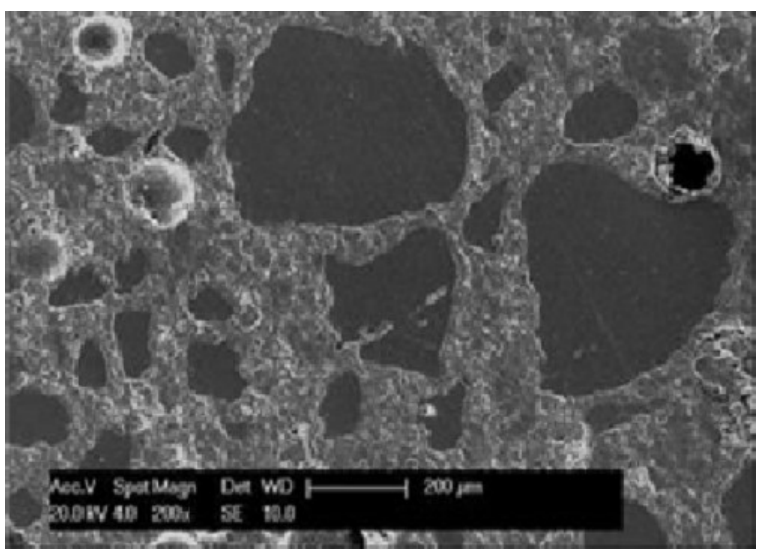

Fig. 6. Entrapped air on samples following no treatment,

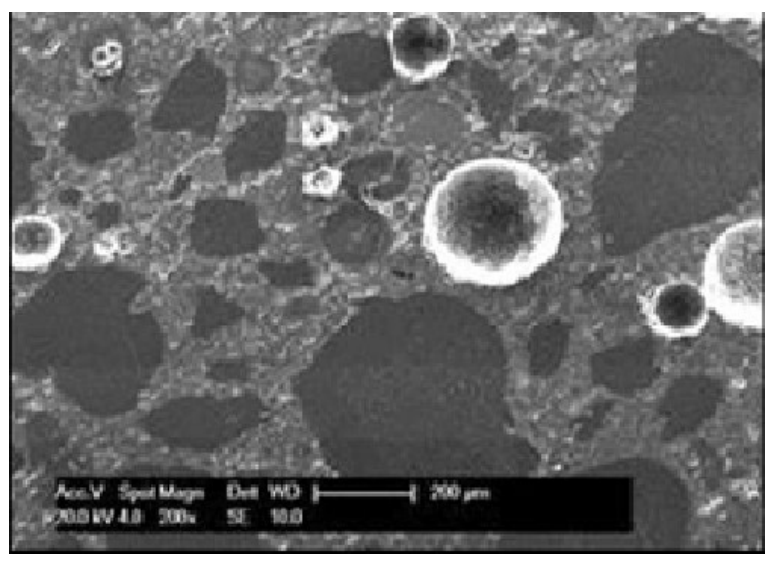

Fig. 7. Entrapped air on samples following heat curing,

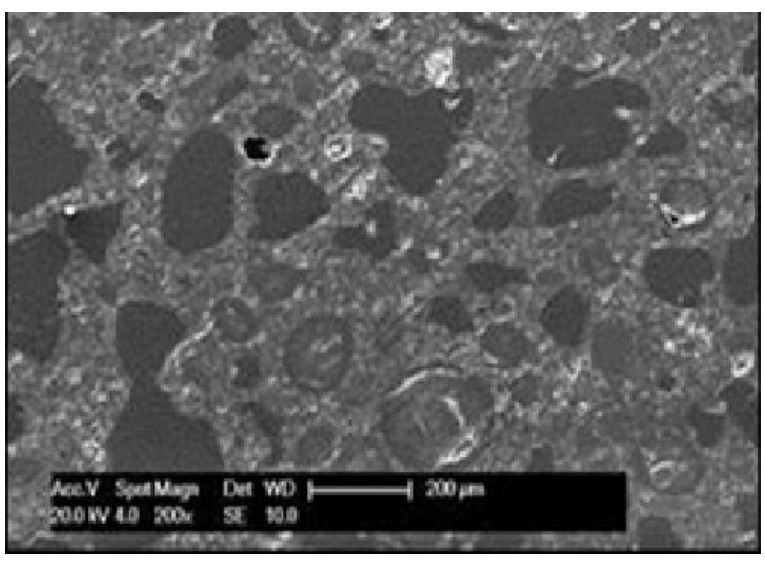

Fig. 8. Entrapped air on samples following pressure, 


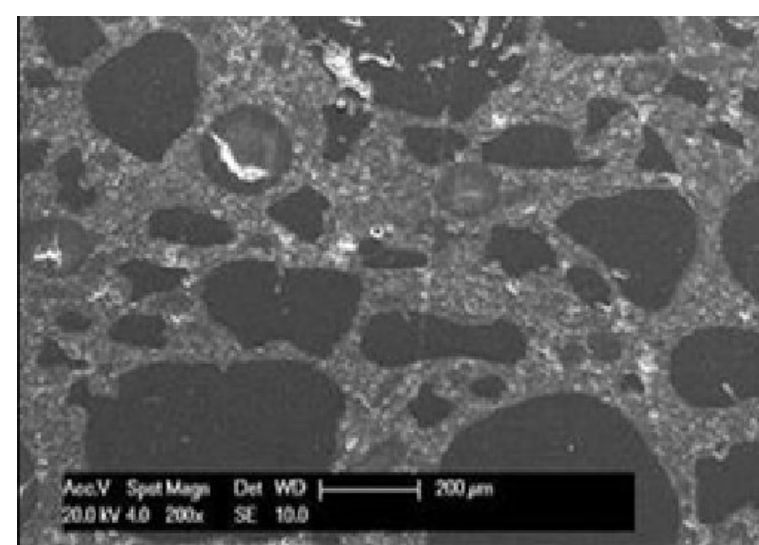

Fig. 9. Entrapped air on samples following pressure and heat curing,

Figure 6 and 7 show that RPC without pressure treatment had some entrapped air pores with a maximum diameter of about $200 \mu \mathrm{m}$. When pressure was applied to fresh mixtures, the number and diameter of large entrapped air pores were reduced by around one order of magnitude (Fig 8 and 9). In addition, the matrix of specimens appeared denser than those without pressure. It is suggested here that some of pores have been closed altogether with spill out of free water, whilst others were changed physically becoming smaller in diameter and greater in number. This finding supports most scholars' statements that applied pressure on fresh mixtures can reduce the pore volume and mean diameter, and consequently increase matrix density $[1,8]$.

\subsubsection{Pore filling after heat curing}

Most scholars agree that heat curing induces a pore filling mechanism caused by the formation of pozzolan-derived $\mathrm{C}-\mathrm{S}-\mathrm{H}$ phases, the rate of formation for which is exothermically driven $[1,6,11]$. At a temperature of $90^{\circ} \mathrm{C}$ it can accelerate the hydration reaction, and therefore transform both the microstructure and microchemistry of RPC [6]. Tam \& Tam [11] found that tobermorite was characterised by plate-like crystals formed at a temperature of around $150{ }^{\circ} \mathrm{C}$, whilst xonotlite was observed as needle-shaped crystals that occur at temperatures above $200{ }^{\circ} \mathrm{C}$. At higher temperatures, between 200 and $250{ }^{\circ} \mathrm{C}$, the chain length of C-S-H can be modified from trimer to pentamer or hexamer, with some dehydroxilation of cement gel due to both acceleration of hydration and the pozzolanic reaction $[5,12]$. The pore filling mechanism of RPC in this study is shown in Figure 10 - 11.

Figure 10 presents the pore inside appeared nearly clear with an irregular coarse surface, and small pores with a diameter of about $1 \mu \mathrm{m}$. The small platy-shaped hydrate, possibly found in RPC at ambient temperature curing, was identifiable as C-S-H [8]. The structure of this $\mathrm{C}-\mathrm{S}-\mathrm{H}$ typically was like a rigid gel which was amorphous or with poorly crystalline structure [10].

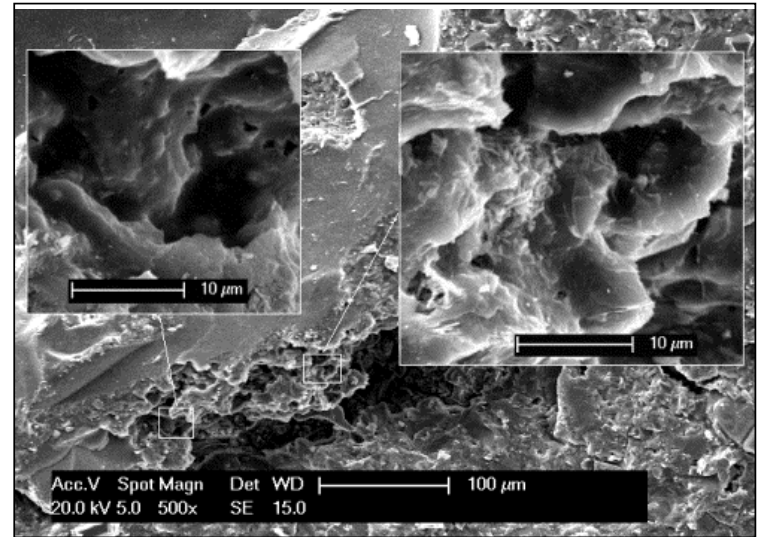

Fig. 10. Morphology on pore without heat curing. Insert: group of ettringite crystal located in pores.

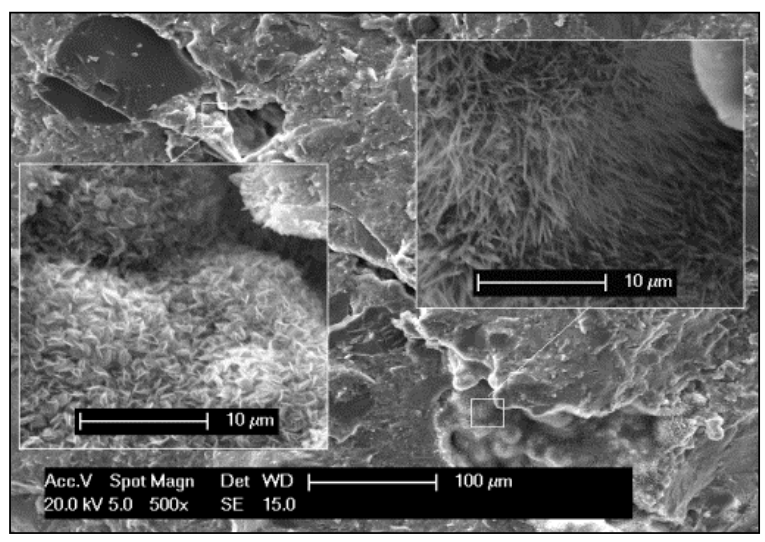

Fig. 11. Morphology on pore with heat curing. Insert: groups of tobermorite (platy-shape) and xonotlite (needle-shape) filled in pores. Heat curing induces pore filling mechanism.

Figure 11 shows some pores of specimens after heat curing, and they were filled by some platy-shaped and needle-shaped crystals. The platy-shaped crystals were identified as tobermorite $\left(\mathrm{Ca}_{4+\mathrm{x}}\left(\mathrm{H}_{2-2 \mathrm{x}} \mathrm{Si}_{6} \mathrm{O}_{17} .5 \mathrm{H}_{2} \mathrm{O}\right)\right.$ or $\left(\mathrm{C}_{5} \mathrm{~S}_{6} \mathrm{H}_{5}\right)$ which has properties such as: a hardness of 2.5 on the Mohs scale, relatively stable with a $\mathrm{CaO} / \mathrm{SiO}_{2}$ molar ratio of 0.83 . The needle-shaped crystals were called xonotlite $\left(\mathrm{Ca}_{6}\left(\mathrm{Si}_{6} \mathrm{O}_{17}\right)(\mathrm{OH})_{2}\right.$ or $\left.\mathrm{C}_{6} \mathrm{~S}_{6} \mathrm{H}_{2}\right)$, with properties similar to those of tobermorite but having a $\mathrm{CaO} / \mathrm{SiO}_{2}$ molar ratio of 1.0 [11].

This observation finds agreement with those of previous scholars $[8,11]$, where high temperature curing could transform C-S-H to tobermorite or xonotlite and fill the pores inside the specimen [17]. The mechanism of the transformation was that heat treatment extracted water from the hydrates, which is then trapped inside the pores. It was firstly transformed to tobermorite, then secondly into xonotlite as a final structure [10,12]. This transformation mainly depended on both the temperature level and the duration of heating [10]. 


\section{Conclusion}

This study has verified the properties of RPC mixtures with reduced cement 379

content (due to replacement by GGBS). The effects of pressure and high 380

temperature curing treatment on compressive strength and paste morphology 381

have also been investigated in three ways, i.e. heating rate, heating duration and 382

heating start time. The conclusion of this study are as follows:

1. A heating rate at $50{ }^{\circ} \mathrm{C} / \mathrm{hr}$ results in the highest compressive strength about $40 \%$ more than these at 10 or $100{ }^{\circ} \mathrm{C} / \mathrm{hr}$ due to the proportional effect on the pozzolanic reaction rate and the volume of microcracks formed in the paste.

2. A heating duration of 48 hours led to a maximum compressive strength (compared to the samples at 12 and 24 hours) due to the acceleration of both reactions; hydration and pozzolanic.

3 . Heat curing applied at 2 days after casting resulted in the maximum compressive strength due to heatinduced acceleration of hydrate phase densification whilst avoiding the risk of microcrack initiation/enlargement resulting from thermal expansion of partially-hardened hydrate phases.

4. High temperature curing could transform $\mathrm{C}-\mathrm{S}-\mathrm{H}$ to tobermorite or xonotlite and fill the pores inside the specimen due to the extraction of water from the hydrates, which is then trapped inside the pores.

5. The optimum condition of heat curing is starting at 2day after casting with a rate of $50{ }^{\circ} \mathrm{C} / \mathrm{hr}$ for 48 hours due to the increase of pozzolonic and hydration reaction rates and the amount of crystal transformation.

\section{References}

1. P. Richard, M. Cheyrezy, Cem. and Conc. Res. 25 (1995).

2. O. Bonneau, C. Vernet, M. Moranville, P.C. Aïtcin, Cem. and Conc. Res, 3012 (2000).

3. V. Matte, M. Moranville, Cem. and Conc. Comp. 21 1 (1999).

4. Y. W. Chan, S. H. Chu, Cem. and Conc. Res. 347 (2004).

5. H. Zanni, M. Cheyrezy, V. Maret, S'Philippot, P. Nieto, Cem. and Conc. Res. 261 (1996).

6. A. Cwirzen, Adv. in Cem. Res. 191 (2007).

7. H. Yazıcı, H. Yiğiter, A.S. Karabulut, B. Baradan, B.,. Fuel, 8712 (2008).

8. H. Yazıcı, M. Y. Yardımcı, S. Aydın, A.S. Karabulut,. Cons. and Buil. Mat. 233 (2009).

9. A. Sadrekarimi,. Jou. of Adv. Conc. Tech. 2 (2004).

10. C. M. Tam, V.W.Y. Tam, K.M. Nga, Mag. of Con. Res. 6210 (2010).

11. C. M. Tam, V.W.Y. Tam, Mag. of Con. Res. 643 (2012).
12. M. Cheyrezy, V. Maret, L. Frouin, Cem. and Conc. Res. 257 (1995).

13. M. Helmi, (Thesis, University of Nottingham, (2016)

14. M. Helmi, M.R. Hall, S.P. Rigby, 33rd Cement and Concrete Science Conference, pp 288-333 (2013).

15. A. M. Neville, Properties of Concrete, (Atlantic Publications Inc, 2011)

16. P. L. Domone, Concrete, (E \& FN Spon, 1996).

17. M. Helmi, M.R Hall, L. A. Stevens, S.P. Rigby, Cons. and Buil. Mat. J. 10515 (2016).

\section{Acknowledgements}

The authors wish to acknowledge the support of the Directorate General of Higher Education (DIKTI) in Indonesia for the research scholarship enabling this work, which was conducted as part of a larger project. 